\title{
A Critical Study of Arab Males and Females Interactional Styles in Formal Face- to- Face Conversations When Using English as a Second Language
}

\author{
Hussain Al-Ali*, Katy Mann \\ Sunderland City, UK \\ Email address: \\ Bh20vp@student.sunderland.ac.uk (H. Al-Ali), katy.mann @sunderland.ac.uk (K. Mann) \\ ${ }^{*}$ Corresponding author
}

Department of Teaching English to Speakers of Other Languages (TESOL), Faculty of Education and Society, The University of Sunderland,

To cite this article:

Hussain Al-Ali, Katy Mann. A Critical Study of Arab Males and Females Interactional Styles in Formal Face- to- face Conversations When Using English as a Second Language. English Language, Literature \& Culture. Vol. 4, No. 1, 2019, pp. 1-7.

doi: 10.11648/j.ellc.20190401.11

Received: January 6, 2019; Accepted: February 27, 2019; Published: March 20, 2019

\begin{abstract}
It is obvious that the differences between Arab males and females interactional styles in formal face-to-face conversations when using English as a second language is interesting and uneasy task at the same time. In the light of the current research paper findings, the linguistic styles of males and females are quite different in regard with the conversation function itself, feedback of the conversation, the dominant gender in the whole conversation, some phonological variations and so on. Females prefer avoiding direct disagreement and maintaining the social rapport with other opposite gender. Females also depend on more easy ways or strategies to get the other speakers engaged in the dialogue as possible. Males, regardless of their status and educational level, seem less professional speakers and less cooperative than females seem. The process of communication among males and females; particularly, in the Arab word is complex since it is ruled by social and religious norms. But this process doesn't indicate that understanding their interactional styles in formal face-to-face conversations in a second language is not possible despite the small number of research papers conducted in such a field. However, subcultures play a basic role in distinguishing between males and females in conversation; meaning that if one gender comprehends other's subcultures, he or she will definitely be able to communicate in a much better way. The current research paper interestingly indicates that males are less fusty than females in dialogues as the last ones actually employ more strategies of politeness than males do. The researcher applied a descriptive method which is considered the most appropriate way for this current research paper; it is the method that describes the phenomena or the real situation as it is available in reality. However, more research papers are preferred to be conducted to highlight the differences between Arab males and females' interactional styles in; specially, formal face-to-face conversations in regards with prosodic characteristics just like pitch and intonation since such types of papers are rare in the Arab world.
\end{abstract}

Keywords: Interactional Style, Gender, Conversation, Phonological Variation

\section{Hypothesis}

The differences between males and females in the language used are complicated. Therefore, focusing on the variations needs a determined frame in regards with the conversation function itself, feedback of the conversation, the dominant gender in the whole conversation, some phonological variations and so on.

\section{Introduction}

Conversations are one of the most important means of communication or functional among people nowadays. However, the communicative competence of males and females regardless of their ethnicity, religion or language are not similar because they have actually different ways to engage in dialogues or conversations to achieve various 
interactional targets. The social factors that impact any social interaction are different. Firstly, the speakers i.e. who are they and with whom they are talking, the social distance between them i.e. do they know each other or not and the scale of status of each speaker engaged in a conversation. Secondly, the social setting of the conversation itself; for example, the language used in the court is totally different from that language used in a café. Thirdly, the topic that speakers are talking about; for example, topics that may be discussed in an academic college are quite different from topics that may be discussed in everyday life dialogues by a family or among friends [3].

\subsection{Gender and Sociolinguistics}

So many research papers in such a field indicated that females tend to use the style of collaborative speech so that they can reveal their support, solidarity and inters in any specific field, while males on the other hand prefer using competitive style in which they prove they are dominating everything during any conversation [6]. For example, women do not tend to interrupt others during the conversation whereas men tend to interrupt and show the dominance and control of topics being discussed. The differences between males and females in the style of communication in face-toface lead both of them to adopt ways to accomplish their different goals as possible as they can [2].

It is improbable to separate language from society. It is well known; as what sociolinguists urged, that not all people speak in the same way whereas it is very easy to identify the region, gender, level of education of anyone from his or her own way of speech. For example, the pronunciation of day in Australia differs from Britain because Australians pronounce it as die. The differences between males and females in terms of pronunciation are very distinguished. For example, the post-vocalic $[\mathrm{r}$ ] is used by women more than men in New York City. However, the phonetic traits are not the only differences between males and females in conversation. There are also other features such as dominance in the solidarity of conversation, phonological variation, repetition, interruption, conversational feedback and the function of the talk itself [12].

A number of linguistic features may distinguish females language in conversation including lexical fillers i.e. well, you see, using of tag questions all the time, high declaratives and intonation i.e. That's actually an excellent idea!, using adjectives; particularly, soft adjectives such as cute, charming and so on even if such a kind of adjectives do not add any meaning to the context itself, lack of humor sense and avoiding use of colloquialisms and slang as possible [9].

On the other hand, males tend to use colloquialisms and slang, swear words with less intensifiers and adjectives than females just to show some sort of dominance when they engage in any dialogue. Females suffer from somewhat tentativeness, uncertainty and lack of confidence because they may find difficulties in providing proofs of what they would like to convince the addressee they may discuss with in a dialogue. So they may use the following phrases or utterances so much I suppose, I feel, I believe, it seems and so on for a persuasion purpose as possible as they can [2].

For standards forms used in language, females use them more than males because the behavior of woman in any society may be seen as a model and ideal one. Therefore, females tend to use standards forms in conversation rather than slang or vernacular. People normally may go up the socioeconomic hierarchy as they use more standards forms. However; according to the norms that rule the relationships between males and females in a specific society, the gender practices from various cultures is not the same. For example, an appropriate linguistic style in conversation is highly expected from females including vocabulary, intonation and so on in the Arab world; otherwise it would be just like a violation against the general social norms if they do not so in the community. Even if females use English as a second language, females are polite and more status-conscious than males who are tough most of the time ; particularly, in the Arab world. But such a matter, as I always observe, can be more frequent with Muslim Arabs rather than Christians who tend to be less tough than others when speaking. The social norms are very strict in this regard, meaning that if men are not tough or highly serious when talking with women, the society itself may consider them as women rather than real men. Consequently, such a matter may be an outrage against men [3].

Males are less conservative in using pronunciation variables than women because; unlike females, males have always got the power as well as more chances to maintain status by often being successful at anywhere and so on. However, females may find it is very important to use the standard form to boost their work place as possible [10]. Some jobs tend to be more appropriate to females rather than males such as receptionists in a call center, secretaries, flight hostesses and so on in which they need to be more conscious and conservative than males based on the following principle "talk well to succeed in your work [4].

I believe it is very difficult to say that all females are conscious and conservative than men or vice versa, but females tend to use phonological variables to build status and membership in the society especially in the Arab world as what we will see later on in this research paper.

\subsection{Gender and Politeness}

The level of politeness in conversation between males and females are determined by four factors: (1) the power of the relationship among or between speakers, (2) the social distance between them, (3) the level of imposition required during threat or insult cases and (4) selecting the higher liking variable that impacts the level of politeness itself. For females it very significant whether it is an insult and an expression of admiration. They tend to operate strategies of positive politeness in any social setting in the community. So they use more prestigious dialect variables than men. [1]

This is true in the Arab world as females are eager to protect the other interlocutors' face without showing any direct disagreement as possible. 


\subsection{Gender and Language in Kuwait}

I believe that males and females do not only differ with regards to biological and psychological formation but also in the way they use the language itself. When the man in Kuwait speaks, he chooses his words carefully and accurately and avoids any words refer to emotions. While women use the emotional language in her speech just like using the following phrases 'I feel', I believe' and so on in order to express their own feelings as well as thoughts. Such a difference between males and females in using language is considered as a basic cause of why they are far away from each other ; particularly, in the Kuwaiti society. Even if they both talk the same language or dialect, they do not talk within the same contexts or targets; meaning that their thoughts, ideas and opinions are quite different from each other. Men are listening more than speaking while females are speaking more than listening. The value of speech is semantically and pragmatically different between males and females. In such a case, troubles and misunderstanding may occur during any conversation between males and females.

There are two parts existed in the brain that are responsible for language. The two parts are existed in women. Therefore, women are excellent in using the language that has to do with thinking, whereas (personal meaning because as what Holmes (1998) stated, it is very necessary to do so ; particularly, when it comes to analyzing males and females interactional styles in formal face-to-face conversations. I found that women concentrated on the personal meaning more often than males did. They did so because they wanted to express their thoughts and feelings when they interacted with their peers in gender and even with males in the same table in which they were sitting on. Females were too sensitive with the topic that was about the causes of increasing the level of divorce in the Kuwaiti Society; particularly, to the information and data they conveyed in the conversation. I really approved such an assumption. One female in extract-1 (See Appendix) was discussing her tension when she was illustrating the emotional factors of why most men in the Kuwaiti society tend to marry again, since all guests gazed her and few of them also looked mistakes to criticize her opinion ; specially, by males who were close to her. However, the answers of males were mostly referential rather than personal "Did you ask yourself why we tend to marry again?" No body is allowed to say something different faraway from the reality!'. One male was attempting to provide some sort of a logical reason to what the first female said who was personally talking [7].

\section{The Study}

\subsection{The Research Question}

There are several intriguing issues in linguistics that need to be highlighted in Arab societies as in how males and females use language differently in any social setting. The main questions of the current research are as follows: (1) Are men and women similar in terms of face-to-face conversations? (2) Do males rely on less politeness strategies than women? (3) What are the conversation strategies and linguistics used by males and females during face-to-face conversations?

\subsection{Participants}

A primary material was used i.e. one formal face to face conversations transcript taken from a social dialogue program broadcasted in The Kuwait channel 2 in. The name of this program is "Social Issues" and it is broadcasted on every Friday in which a group of Arab social analysts in both genders sitting around one table and discussed a social issue which was about the causes of increasing the level of divorce in the Kuwaiti Society.

\subsection{Data Collection}

The foundation of the current research paper depended on a very careful and detailed observation- mainly by using sociolinguistics and conversation analysis- of a selected episode from the mentioned selected program

\section{Findings}

A sociolinguistics and conversation analysis was applied for the current research paper to analyze the way of how males and females use language in any social setting to be a theoretical framework [8]. Consequently, the current paper is useful to relate the conversation analysis with sociolinguistics. Moreover, to highlight the gender differences, a number of possible factors that influence the relationship among males and females in face-to-face conversation are included

\subsection{Function of the Talk}

I analyzed the conversation function with distinguishing between the referential meaning and the personal meaning because as what Holmes (1998) stated, it is very necessary to do so; particularly, when it comes to analyzing males and females interactional styles in formal face-to-face conversations. I found that women concentrated on the personal meaning more often than males did. They did so because they wanted to express their thoughts and feelings when they interacted with their peers in gender and even with males in the same table in which they were sitting on. Females were too sensitive with the topic that was about the causes of increasing the level of divorce in the Kuwaiti Society; particularly, to the information and data they conveyed in the conversation. I really approved such an assumption. One female in extract-1 (See Appendix) was discussing her tension when she was illustrating the emotional factors of why most men in the Kuwaiti society tend to marry again, since all guests gazed her and few of them also looked mistakes to criticize her opinion ; specially, by males who were close to her. However, the answers of males were mostly referential rather than personal "Did you ask yourself why we tend to marry again?" No body is allowed to say something different faraway from the reality!". One male was attempting to provide 
some sort of a logical reason to what the first female said who was personally talking.

\subsection{Conversational Feedback}

Another significant factor in differentiating the language of males and females is conversational feedback. Males seemed less cooperative speakers or conversationalists; they did not give enough feedback to the partners in front of while females actually did. That's what Holmes (2008) exactly proved when he urged that females in most conversations prefer to give positive and good feedback regardless of the issue posed in order to maintain the other participants' faces as possible as they can. For instance, I found that females tended to produce more utterances repetition, agreement of the other guests available in the same targeted dialogue program. They also produced encouragement and politeness phrases such as fine, so nice, wonderful, cool and so on. Females depended on minimal responses rather than forward disagreement in order to boost them and to show they are good listeners with a highly active attention [5]. On the other hand, men seemed quite competitive than women who were so supportive during the conversation. So women showed some sort of agreement with men because as what Caotes (1998) indicated, the objective of the engagement of women during the analyzed conversation is solidarity to keep the social relationship good with the other peers [2].

I noticed that in Kuwait Society those females do not threat each other face-to-face; particularly, when they sitting with other people. In extract (2), one woman answered the other one the following: "Honestly, I do not like any woman to say something different from my view; particularly, when it comes to a serious problem like marriage and divorce in Kuwait; because we women are all in same mode. We are all victims in the same society. We are not arrogant women but honest one.." On the other side, another woman provided utterances of positive feedback like "Just like me", definitely, yeah"and so on. The intonation in such utterances was quite high. Also those utterances mostly followed the strategies of agreement and encouragement. They tried to save each other face as possible by saying "I agree with you." Another female expressed politely as a method to show some sort of gratitude to another female who agreed with her in a certain point by saying "You are totally right!"Oh, Mona you got my point very well." I observed that females who did not know each other very well tended to express a sense of solidarity with. They praised admiration and appreciation to each other. The conversation generally was so active and there was not any time to stop expressing solidarity among females who were looking to each others as if they have a previous intimacy, whereas men tended to be far away from each others as if each one is living in an isolated island without even responding or interacting with each others' answers.

\subsection{Dominance in Conversation}

In the light of the mixed -gender dialogue, females and males tended to initiate more issues to prevent any silent moment and keep the conversation going on as possible. I quite agree with the assumption that females dominated the whole conversation since the initiated topics they posed were more than males did. Therefore, the direction of the whole conversation went as females like exactly to be. As a result, I do not believe that as what so many sociolinguists believe dominance in conversation has to do with interruption because the more reasons, factors and topics are initiated, the more he or she may have a control over any dialogue. I also observed that females initiated more than men regardless of the level of solidarity or intimacy among speakers in the conversation itself. In extract No.(3), a good example of how females dominated the conversation very well to keep its mainstream. The reasons of increasing the level of divorce in the Kuwaiti society were initiated respectively. For example, one of the female guests asked a man "when will you divorce your wife?" Then the same female speaker initiated again the following "when will you divorce or marry again? "Later on, she asked the man twice again by using an utterance in which she proved that she had a feeling toward him that she hoped he will never divorce his own wife or marry a new one again.

\subsection{Repetition in Conversation}

I noticed three mainly cases of repetition in the targeted conversation that is a very common phenomenon in the Arab world even if they use English as a second language. They tended to use words that begin with the same sounds, repeated the same grammatical structures several times and switched respectively the order of elements. In this regard, speakers who engaged in any dialogue tend to repeat utterances or whatever just to prove that they listen well and to show that they are able to understand what they actually listen to. Another benefit of repetition is that it is a good way to solve problems during the conversation. That is what linguistically called self-correction and other's correction. A cohesive relationship can be created in various phrases, sentences or utterances [8].

I also noticed that males and females tended to use repetitions several times so that they can signal rapport between each others. However, males, according to the targeted conversation, tended to produce less repetitions than females whether between their peers or with other females available. The extract (4) shows that one woman presented a new topic and asked a man close to her about how he could spend his time with is wife and children: "What should you do with your wife and children?" Do you spend your all time outside the house? "She asked such questions and corrected her self in the following question in another way as follows: Do you know that you are the only one who is responsible for your wife and children? "Do you think spending most of your time with your friends in the café impact negatively on your family? "Such repetitions in this case are functional because the women who asked such questions several times targeted to illustrate what has been said in the first question she asked. Another woman tried to force the other man to get engaged in the dialogue by asking the following question "You may leave your family and spend your time on the Internet? "Then 
she asked the same question but with different strategy this time by using tag-question: "Right?" Men also used repetitions but less than women did; for example, they uttered the following sentences: "You have nothing to do with my own affairs. Never okay! I would like to do," Who is the man here? Hah? Who? Don't you get that?"I believe that males used such repetitions to get the other females follow them and to show they are able to understand what they are talking about. So they wanted not to show any embarrassment or confusion as men supposed to be in front of females. For instance, one man used unintentionally the following sentence "I do that .... I do that for you and our children". He just attempted to emphasize what has been initially said and to justify his position. following phrase "Like to be Behind scenes" was repeated again by the similar woman in order to ensure the other man comprehended what was initially asked. The man also used the similar phrase "Like to be Behind scenes" in order to prove he listened and understood what the same woman has asked him.

\subsection{Solidarity}

According to the analyzed conversation, I observed that; just like what Holmes (1998) explained, females tended to concentrate on the others' feelings toward the partners they were engaged in the conversation. As a result, females showed some sort of encouragement and sympathy because females naturally made of a cooperative nature even in mixed - gender dialogues. They interacted with males sympathetically; particularly, when males suffer from psychological troubles or a disease. So, females in the targeted conversation succeeded in securing agreement and drawing attention signs to the males' faces. One male in the conservation as mentioned in extract No.(5) seemed embarrassed because he had a problem with his own wife and he was anxious that his wife may expel him from the house. So he may sleep outside the house and even think about looking for another more merciful woman instead. Moreover, he tried to show he is indifferent without any attention to apologize for her. At the beginning, he did not show the real reason for his embarrassment using an ironic utterance as follows "What? Nothing." However, the female attempted to elicit information. But at the end they assured him that every thing will be okay using soft utterances such as okay, Don't worry, So what?

The last female used what is linguistically called codeswitching here either to show off or to prove that she is a prestigious as well as to highlight a minimum degree of solidarity because both speakers have a family and they actually know such things are normally supposed to be happened at anytime soon or later.

\subsection{Phonological Variations}

It is well-known that both males and females are phonologically different because of the biological differences such as the mouth, vocal cords and throat dimension and certain ways suitable to the gender that are identified with by anyone. I noticed in the light of the targeted conversation that males have got higher voice than females who really have breathier voice quality than males. They made themselves more desirable to the opposite males with associating with a high level of intimacy despite the fact that males have got a larger pitch or tone range than females [5].

One male in the conversation attempted to use fluent English to appeal the attention of the opposite gender and to show himself as an educated speaker. From my own experience I believe that the majority of foreign speakers; particularly, those who use English language as a second one, tend to use fluent English words or phrases even within Arabic to show off; particularly, when they interact with females. They think that by such a way they seem very prestigious and preferable for females who may speak English less fluency.

\section{Conclusion}

There are some specific factors that influence the relationship among males and females in face-to-face conversation when using English as a second language in the Arab world. First, females tend to concentrate on the personal meaning more often than males do. They do so because they are more likely to express their thoughts and feelings when they interact with their peers in gender and even with males. Second, males are less cooperative speakers or conversationalists than females; they rarely give enough feedback to the partners in front of while females actually do in most cases. Third, females often tend to dominate the whole conversation more than males do. Therefore, the direction of most dialogues usually goes as females would like exactly to be. Fourth, it seems that males and females use repetitions several times so that they can signal rapport between each others. However, males produce less repetitions than females whether between their peers or with other females. Fifth, with regard to solidarity, females often show some sort of encouragement and sympathy because they naturally made of a cooperative nature even in mixed gender dialogues than males do. Finally, males have got higher voice than females who really have breathier voice quality than males. That's because they are both different in vocal cords and throat dimension.

\section{Appendix}

\section{Extract No. (1)}

F: I feel men are hasty and do not feel what women do really want! I believe that men are all selfish in Kuwait because they do not appreciate the great role of their wives in the society. I feel that all they think about just food and sleep. I realize that they spend most of their time outside the house leaving their wives alone to take care of his won children as well as duties and responsibilities of the house itself.

M: "All right. Did you ask yourself why we tend to marry again?" No body is allowed to say something different faraway from the reality!". You have to be more honest 
faraway from any feelings or personal sensations.

F: I am thinking of emotional factors that push men to marry again

M: No, you actually do not talk about the real situation. 'No body is allowed to say something different faraway from the reality!"

Extract No. (2)

F1: Honestly, I do not like any woman to say something different from my view; particularly, when it comes to a serious problem like marriage and divorce in Kuwait; because we women are all in same mode. We are all victims in the same society. We are not arrogant women but honest one

F2: Oh ...Just like me.

F3: Definitely, you are explaining the issue very well. Men in our society should feel and listen to us as frank women.

F1: Yeah!

F2: Oh, Mona you got my point very well. Wonderful!

F3: Thanks. Moreover, more social studies and research papers must be conducted in our local society to find the real reasons of increasing the level of divorce in the Kuwaiti Society

F1: You are totally right.

F2: I agree with you

F1: Oh, that would be so nice and cool

F3: Fine........

Extract No. (3)

F: When will you divorce your wife?

M: It is not an appropriate way to ask a question!

F: Oh please, try to be honest.

$\mathrm{M}: A h \ldots . . .$.

F: When will you divorce or marry again?"

M: hahahahahahahahah (a big laugh)

F: Again you're trying to avoid my question. When will you divorce or marry again?"

M: why me? Why are you asking me such a question?

F: I feel if you answer my important question, you as an example of men, will find easily what are the silly factors that push you for example and other men in our society to marry or divorce your wives as well as finding the reasonable solutions of our serious issue....

F2: Oh, that would be so nice

F3: I agree with you

F1: Thanks a lot.

(All other males were silent without even looking to each other)

Extract No. (4)

F1: What should you do with your wife and children?"Do you spend your all time outside the house?"

M1: No.... ammm ...sometimes.

F: Do you know that you are the only one who is responsible for your wife and children? "Do you think spending most of your time with your friends in the café impact negatively on your family?"

M1: No

F2: You may leave your family and spend your time on the Internet? Right?
M1: You have nothing to do with my own affairs. Never okay! I would like to do. Who is the man here? Hah? Who? Don't you get that?

F1: Really!

M1: I do that .... I do that for you and our children.

F2" How it comes? What are you talking about?

M1: I am a man by the way. My place is not inside the house.

F1: Like to be behind the scenes!

M1: Like to be behind the scenes!

Extract No. (5)

M1: I really feel embarrassed.

F1: Why?

M1: What? Nothing.

F2: What happened?

M1: I have a problem with my own wife.

F1: What problem?

M1: Before I come to this program, she saw me talking with one girl in the supermarket.

F1: So what?

M1: She may expel me form the house tonight.

M2: hahahhahahah. Oh my God.

F1: Don't worry. It is not s serious problem. You can explain her the real situation

F2: That's right. Everything will be okay. I remembered a similar situation happened with me and my wife, but I forgave him. It was just a misconception.

\section{References}

[1] Brown, P. \& Levinson, S. (1987). Politeness: Some Universals in Language Usage. Cambridge: Cambridge: University Press.

[2] Coates, J. (1998) Language and Gender: A Reader. Blackwell.

[3] Harahsheh, A. (2014). Language and Gender Differences in Jordanian Spoken Arabic: A Sociolinguistics Perspective, Theory and Practice in Language Studies, 4(5): 872-882.

[4] Goddard, A. \& Patterson, L. (2000). Language and gender, London: Routledge.

[5] González, D. (2011). Phonetic differences between male and female speech (online). Available form: https://prezi.com/kyk6mg4u8ff/phonetic-differences-between-male-and-femalespeech/ [Accessed on May 21st , 2018].

[6] Holmes, J. (2008). Introduction to Sociolinguistics . Pearson Longman: New York.

[7] Holmes, J. (1998). Complimenting $-A$ positive Politeness Strategy: Language and Gender. Oxford: Blackwell Publishers.

[8] Hutchby, I., \& Wooffitt, R. (1998). Conversation Analysis: Principles, Practices and Applications. Cambridge: Polity Press.

[9] Johnstone, B. (2008). Discourse Analysis. USA: Blackwell Publishing.

[10] Lakoff R. (1975) Language and Women's Place Harper and Row, New York. 
[11] Trugdill, P. (1968). Sex and Covert Prestige. In Coates. Language and Gender: A Reader. Oxford: Blackwell Publishers.
[12] Wallace, M. J. (1998). Action Research for Languages. Cambridge: Cambridge University Press. 